\title{
Hygrothermal Behavior of Earth-Based Materials: Experimental and Numerical Analysis
}

\author{
Meriem Saidi $^{a, b^{*}}{ }^{*}$, Amel Soukaina Cherif $^{c}$, Ezeddine Sediki $^{a}$, Belkacem Zeghmati $^{b}$ \\ a Thermal Radiation Research Unit, Faculty of Science of Tunis, University of Tunis El Manar, 2092, Tunis. Tunisia \\ ${ }^{\mathrm{b}}$ Laboratory of Mathematics and Physics, University of Perpignan Via Domitia, France \\ ${ }^{\mathrm{c}}$ Laboratory of Energy, Heat and Mass Transfer, Faculty of Science of Tunis, Tunisia
}

\begin{abstract}
Bio-based building materials such as earth bricks are attracting renewed interest throughout the world due to their thermal and environmental properties.

In this work, a numerical study of the hygrothermal behavior of building walls consist of compressed earth bricks (CEB) and stabilized earth bricks (SEB) was performed. A two-dimensional Luikov model for evaluating the temperature and the moisture migration in porous building materials was proposed. The coupled heat and moisture transfer problem was modeled. The governing equations of a mathematical model were solved numerically with the finite difference method. Input parameters in the model and their dependency on stabilizers content were determined by laboratory experiments.

In order to specify the effect of chemical stabilization on the heat and mass transfer within studied materials, average moisture content and temperature were presented as a function of time. Results show that the addition of chemical stabilizers enhances the heat transfer through the earthen materials and reduces their water vapor permeability.
\end{abstract}

\section{Introduction}

Earth is one of the oldest construction materials that was used since the birth of humanity. Nowadays, earth-based materials present a great alternative to conventional building materials which contain chemicals that may be harmful to people and the environment. Since they have several environmental, social and economic benefits, their use contributes to minimize the negative effects that our built environment can have on the planet while increasing the energetic economy[1]. It present a high potential to create a healthy environment and to regulate the hygrothermal conditions inside a building for its occupants[2]. Thus, earth-based walls have hygrothermal performance that stabilize the relative humidity inside the building and consequently increase indoor comfort.

However, earth materials are suffering from high sensitivity to environment changes [2]. Building walls in service conditions are subjected to variable climatic conditions, which can create a moisture transfer within their components and contribute to its rapid deterioration [3]. In recent years, stabilization, which refers to the process of mixing additives with soil to improve its volume stability, strength, permeability and durability [4], became a

\footnotetext{
"Corresponding author: E-mail: meriem.saidi@fst.utm.tn
}

common approach to prevent water attacks and enhance resistance to climate change.

Although the addition of chemical stabilization enhances the engineering properties of soil [5], it is not the case for their hygrothermal properties [6]. In this context, several researches have been focused on the impact that stabilization may have on the thermal and hygric properties of earth bricks. Among such studies, Arrigoni et al. [7] carried out experimental study to evaluate the stabilization effects on the moisture buffer capacity of rammed earth. Fopossi et al. [8] studied the effects of stabilizers on water absorption of compressed earth blocks. The findings showed that the chemical treatment decreases the hygroscopicity for the studied earth-based materials and increases its water vapor resistance. Balagi et al. [9] investigated the influence of varying mix proportions on thermal performance of soil-cement blocks. They found that the addition of stabilizer increases the thermal conductivity of the blocks.

The objective of this paper is to investigate the hygrothermal behavior of earth-based walls. In order to study coupled heat and moisture transfer within building walls, the coupled equations of Luikov's model were solved. A numerical code, developed for prediction of heat and moisture transfer in porous materials, was used to simulate the temperature, moisture content profiles within 
the earth-based materials. The results allow to show the impact of chemical stabilization process on the hygrothermal behavior of studied materials.

\section{Nomenclature}

$\mathrm{T}$ : Temperature $(\mathrm{K})$

w: Moisture content ( $\mathrm{Kg} / \mathrm{Kg}$ d.b)

$\alpha$ : Thermal diffusivity of the porous material $\left(\mathrm{m}^{2} / \mathrm{s}\right)$

D: Mass diffusivity of the porous material $\left(\mathrm{m}^{2} / \mathrm{s}\right)$

Lu: Luikov number $L u=D / \alpha$

Ko: Kosovitch number $K o=L_{v} \cdot w / C_{p} . \Delta T$

Pn: Posnov number $P n=\delta . \Delta T / w$

Bi: Biot number

$\lambda$ : Thermal conductivity (W/m.K)

$\varepsilon:$ Phase conversion factor

$\delta$ : Thermal gradient coefficient for transfer of vapor $\left(\mathrm{K}^{-1}\right)$

\section{Problem Formulation}

\subsection{Description of physical problem}

The processes of heat and mass transfer are highly coupled within porous materials. The modeling of this physical phenomena coupled heat and moisture transfer in building materials usually involves theories of Philip and De Vries [10], Luikov[11] and Whitaker[12]. These models differ in the choice of the variable and driving potential.

The studied earth-based materials considered as open porous media are containing variable proportion of water and mixture of vapor and air. The phase changes and the moisture migration occurring within the building material are always linked to heat transfer. Hence, the choice of model is made to take into account the different interaction between all phases and their contribution on the heat and mass transfers within the wall.

In this paper, a two-dimension Luikov model is proposed for evaluating the simultaneous heat and moisture migration in studied materials subjected to different boundary conditions. Temperature and moisture content are chosen as the principal driving potentials. Initially, uniform temperature and moisture content profiles are assumed. The boundaries are in contact with the surrounding hot air. In the model, these boundaries are represented using convection boundary conditions for the temperature and moisture content.

\subsection{Assumptions}

The model is based into the following set of assumptions:

-The thermo-physical proprieties are assumed constants,

-Porous material is assumed to be homogeneous, isotrope and non-deformable,

-The heat transfer by radiation is negligible,
-The initials conditions of the moisture content and temperature distribution in the wall are uniforms.

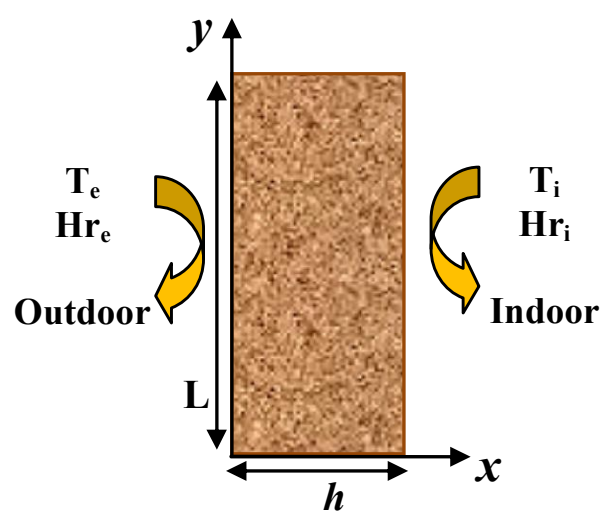

Figure 1

Schematic of building envelope

\subsection{Governing Equations}

The governing equations, based on the theory of Luikov [11], to model heat and mass transfer through studied materials, are given by Eqs. (1) and (2):

Energy conservation

$$
\begin{aligned}
& \frac{\partial T}{\partial t}=\alpha\left(\frac{\partial^{2} T}{\partial x^{2}}+\frac{\partial^{2} T}{\partial y^{2}}\right)+\varepsilon \cdot \frac{L_{v}}{C_{p}} \frac{\partial w}{\partial t} \\
& \text { Mass conservation } \\
& \frac{\partial w}{\partial t}=D\left(\frac{\partial^{2} w}{\partial x^{2}}+\frac{\partial^{2} w}{\partial y^{2}}\right)+D \cdot \delta \cdot\left(\frac{\partial^{2} T}{\partial x^{2}}+\frac{\partial^{2} T}{\partial y^{2}}\right)
\end{aligned}
$$

\subsection{Initial conditions}

For $t<t_{0}$

$$
\begin{aligned}
& T\left(x, y, t_{0}\right)=T_{0} \\
& w\left(x, y, t_{0}\right)=w_{0}
\end{aligned}
$$

\subsection{Boundary conditions}

For $t \geq t_{0}$

- $x=0 ; 0 \leq y \leq L$ (Surface in contact with external air)

$\left.-\lambda \frac{\partial T}{\partial x}\right)_{0, y}=h_{t_{e}}\left(T_{e}-T(0, y)\right)-(1-\varepsilon) \cdot L_{v} \cdot h_{m_{e}} \cdot \rho \cdot\left(w(0, y)-w_{e}\right)$

$\left.\left.D \frac{\partial w}{\partial x}\right)_{0, y}+D \cdot \delta \cdot \frac{\partial T}{\partial x}\right)_{0, y}=h_{m_{e}}\left(w(0, y)-w_{e}\right)$

- $x=h, 0 \leq y \leq L$ (Surface in contact with internal air)

$\left.-\lambda \frac{\partial T}{\partial x}\right)_{h, y}=h_{t_{i}}\left(T(h, y)-T_{i}\right)-(1-\varepsilon) \cdot L_{v} \cdot h_{m_{i}} \cdot \rho \cdot\left(w(h, y)-w_{i}\right)$

$\left.\left.D \cdot \frac{\partial w}{\partial x}\right)_{h, y}+D \cdot \delta \cdot \frac{\partial T}{\partial x}\right)_{h, y}=h_{m_{i}}\left(w_{i}-w(h, y)\right)$ 


$$
\begin{array}{r}
y=0 / y=L ; 0 \leq x \leq h \\
\left.\left.\frac{\partial T}{\partial y}\right)_{x, 0}=0 ; \frac{\partial w}{\partial y}\right)_{x, 0}=0
\end{array}
$$

The two equations (5) and (7) express the heat flux in terms of convection heat transfer and the phase-change energy transfer. Eqs. (6) and (8) show a water content difference, $\Delta w$, on their right-hand side. The two terms on the left-hand side describe the supply of moisture flux under the effect of a temperature and a moisture gradients, respectively.

In equations (6) and (8), the wall equilibrium moisture, $w$, is determined using the following equation:

$$
w=\frac{c_{s}}{1-c_{s}}
$$

when $c_{s}$ is the wall vapor concentration of air and it can be expressed from:

$$
c_{s}=0,622 \cdot \frac{H r \cdot P_{v s}}{P-0,378 \cdot H r \cdot P_{v s}}
$$

$\mathrm{P}$ is the atmospheric pressure whereas $\mathrm{P}_{\mathrm{vs}}$ is the partial pressure of saturated vapor at the wall temperature. $\mathrm{P}_{\mathrm{vs}}$ is given by the Bertrand formula [13]:

$$
\log \left(\mathrm{P}_{\mathrm{vs}}(\mathrm{T})\right)=17,442-\frac{2790}{\mathrm{~T}}-3,868 \log \mathrm{T}
$$

\subsection{Dimensionless formulation}

Equations (1)-(2) and boundary conditions (5)-(9) were transformed by introducing the following dimensionless variables and functions.

$$
x^{+}=\frac{x}{L} ; y^{+}=\frac{y}{L} ; T^{+}=\frac{T-T_{0}}{T_{e}-T_{0}} ; t^{+}=\frac{\alpha \cdot t}{L^{2}} ; w^{+}=\frac{w}{w_{0}}
$$

On introducing the dimensionless variables (13), Eqs. (1)-

(2) can be written in dimensionless form as:

$$
\begin{aligned}
& \frac{\partial T^{+}}{\partial t^{+}}=\frac{\partial^{2} T^{+}}{\partial x^{+^{2}}}+\frac{\partial^{2} T^{+}}{\partial y^{+^{2}}}+\varepsilon \cdot K o \frac{\partial w^{+}}{\partial t^{+}} \\
& \frac{\partial w^{+}}{\partial t^{+}}=L u\left(\frac{\partial^{2} w^{+}}{\partial x^{+^{2}}}+\frac{\partial^{2} w^{+}}{\partial y^{+^{2}}}\right)+L u \cdot P n\left(\frac{\partial^{2} T^{+}}{\partial x^{+^{+}}}+\frac{\partial^{2} T^{+}}{\partial y^{+^{2}}}\right)
\end{aligned}
$$

where $K o, L u$ and $P n$ are respectively the Kossovitch, Luikov and Posnov numbers, the definitions of which are given in the Nomenclature.

In view of this consideration, the initial conditions and the material balance for heat and moisture at the surface can be written as:

$$
\begin{aligned}
& \text { For } t^{+}<t_{0}^{+}: \\
& \qquad T^{+}=0, w^{+}=1 \\
& \text { For } t^{+} \geq t_{0}^{+} \\
& \bullet \quad x^{+}=0 ; 0 \leq y^{+} \leq 1 \\
& \frac{\partial T^{+}}{\partial x^{+}}=B_{i_{e e}}\left(T^{+}-1\right)+(1-\varepsilon) \cdot K o \cdot L u \cdot B_{i_{m e}} \cdot\left(w^{+}-\left(w_{e} / w_{i}\right)\right) \\
& \frac{\partial w^{+}}{\partial x^{+}}+P n \cdot \frac{\partial T^{+}}{\partial x^{+}}=B_{i_{m e}}\left(w^{+}-\frac{w_{e}}{w_{0}}\right)
\end{aligned}
$$

$$
\begin{gathered}
\bullet \quad x^{+}=h / L ; 0 \leq y^{+} \leq 1 \\
\frac{\partial T^{+}}{\partial x^{+}}=B_{i_{i}}\left(\frac{\left(T_{i}-T_{0}\right)}{\left(T_{e}-T_{0}\right)}-T^{+}\right)-(1-\varepsilon) \cdot K o \cdot L u \cdot B_{i_{m i}} \cdot\left(w^{+}-\frac{w_{i}}{w_{0}}\right) \\
\frac{\partial w^{+}}{\partial x^{+}}+P n \cdot \frac{\partial T^{+}}{\partial x^{+}}=B_{i_{m i}}\left(\frac{\left(w_{i}-w_{e}\right)}{\left(w_{0}-w_{e}\right)}-w^{+}\right) \\
\bullet \quad y^{+}=0 / y^{+}=1 ; 0 \leq x^{+} \leq h / L \\
\frac{\partial T^{+}}{\partial y^{+}}=0 ; \frac{\partial w^{+}}{\partial y^{+}}=0
\end{gathered}
$$

The model equations have been numerically translated using a Fortran program to facilitate calculations. The objective now, is to determine the distribution of the dimensionless temperature and moisture content fields, $\mathrm{T}(\mathrm{x}, \mathrm{y}, \mathrm{t}), w(\mathrm{x}, \mathrm{y}, \mathrm{t})$, respectively in earth brick wall.

\section{Numerical Resolution}

In the present study, Luikov's equations were solved and the resultant model was validated. Furthermore, the effect of chemical stabilization on the hygrothermal behavior of the studied earth bricks is studied.

The heat and mass transfer equations given by Eqs. (14) and (15) with initial and boundary conditions (16)-(21) have been discretized by means of an implicit finite difference scheme. The resulting algebraic system has been treated by the iterative Gauss-Seidel procedure.

\subsection{Model validation}

The numerical code has been successfully validated by comparing the present solutions with data available in the literature.

The predicted center and surface temperature and moisture evolutions inside a spruce sample are compared with the analytical solution of Liu and Cheng [14] for onedimensional problem of heat and mass transfer [15]. The operating conditions used for the test case is given from Liu and Cheng [14].

Considerably high agreement was found between the numerical results and the analytic model. The maximum difference between numerical and analytical results is less than $3.0 \%$ for temperature distribution and less than $4.0 \%$ for moisture content distribution [15]. Therefore, it can be stated that this physical model can be used to investigate hygrothermal behavior of porous building materials.

\subsection{Materials proprieties}

In this study, we presented a numerical investigation of the hygrothermal behavior of compressed earth bricks (CEB) and stabilized earth bricks with cement (SEBC) or with lime (SEBL). We have chosen to make mixtures with an identical matrix and different dosages of chemical stabilizers by replacing an amount of dry soil with Ordinary Portland Cement (CEM II A-L 32.5 N) or highcalcium hydrated lime (CL 90-S). A variety of earth bricks with different compositions of cohesive soil, cement and lime are studied. The used ratio of stabilizers 
were respectively $5,8,10$ and $12 \%$ by weight of dry soil. To determine the effect of stabilization on the hygrothermal behavior of the studied earth bricks, CEB is considered as the reference mixture for the study.

The thermo-physical and hygric properties of different materials are required to solve the simultaneous heat and mass transfer equations. To guarantee the accuracy of the input parameters in the mathematical model, the materials properties are measured in the laboratory.

First, the studied earth bricks specimens were prepared with a density $(\rho)$ of approximately $1750 \mathrm{~kg} / \mathrm{m}^{3}$. The thermal conductivity measurements are carried out using the method of the box. Stabilizers dependence was evaluated as (figure 2):

$$
\begin{aligned}
& \lambda=-0,0041(\mathrm{CC})^{2}+0,1135(\mathrm{CC})+0,3323 \\
& \lambda=-0,0051(\mathrm{LC})^{2}+0,1138(\mathrm{LC})+0,3487
\end{aligned}
$$

where $\mathrm{CC}$ and $\mathrm{LC}$ are respectively the cement and lime content.

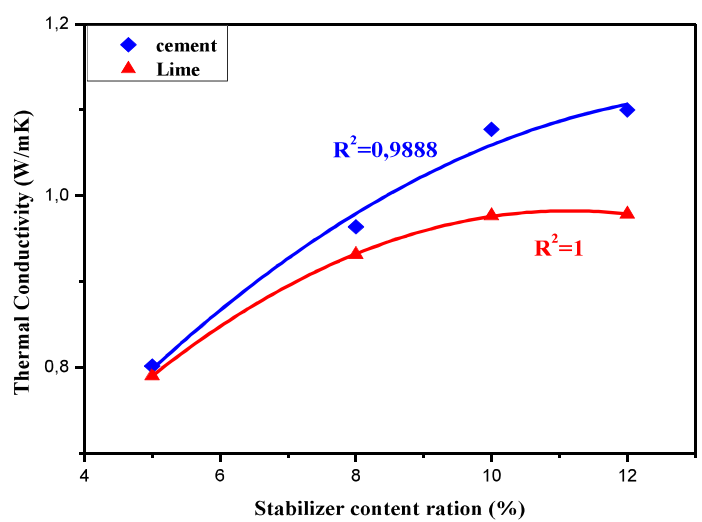

Figure 2

The variation of thermal conductivity with cement and lime contents of the stabilized earth bricks

The main sorption isotherms were determined gravimetrically at $25^{\circ} \mathrm{C}$ using climatic chamber that can create environment at $\mathrm{Hr}$ between $40 \%$ and $97 \%$. Figures 3(a-b) show the experimental results, for relative humidity up to $40 \%$ of the main desorption isotherms.

The experimental data are fitted with the Henderson's semi-theoretical model [16], which expresses the relationship between the equilibrium moisture content and the relative humidity at a given temperature:

$$
\mathrm{Hr}=1-\exp \cdot\left(-\mathrm{k} \cdot \mathrm{T} \cdot \mathrm{w}^{\mathrm{n}}\right)
$$

The Henderson model is considered to be among the most appropriate sorption model for this purpose. It allows us to obtain water content for relative humidity less than $40 \%[6]$. The mass diffusivity of the porous material (D) is determined using the following equation:

$$
D=\delta_{p} \cdot \frac{P_{v s}(T)}{\rho} \cdot \frac{1}{\zeta}
$$

Where $\delta_{p}(\mathrm{~kg} / \mathrm{m} . \mathrm{s} . \mathrm{Pa})$ is the water vapour permeability and $\zeta$ the moisture capacity. $\delta_{p}$ can be obtained from McGregor (2014) [17] and $\zeta$ is usually determined by the slope of the adsorption curve (figure 3 ), given by the following equation:

$$
\zeta=\frac{\partial w}{\partial H r}
$$
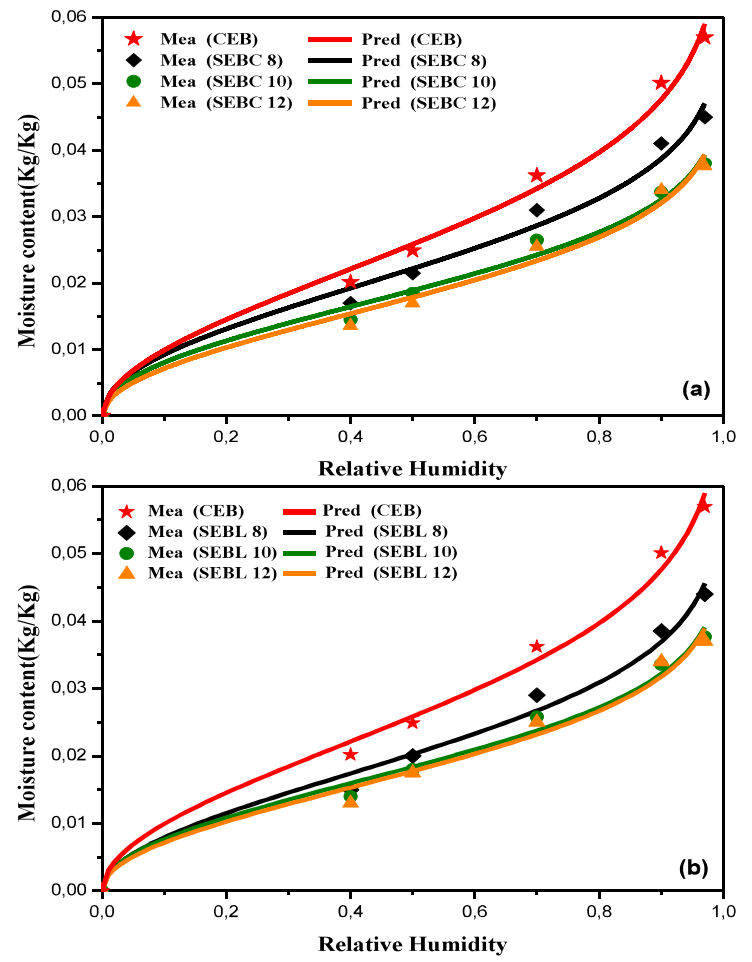

Figure 3

Experimental and predicted (Henderson model) adsorption isotherms of CEB, SEBC (a) and SEBL (b)

\section{Results and discussions}

The set of the results presented in this paper relates to the study of simultaneous heat and mass transfers that occur in wall made with $\mathrm{CEB}$, three walls made with cement stabilized earth bricks (SEBC8, SEBC10, SEBC12) and three walls made with lime stabilized earth bricks (SEBL8, SEBL10, SEBL12). Initially, the earth brick wall is subjected to an initial temperature $\mathrm{T}_{0}=20^{\circ} \mathrm{C}$ lower than the ambient temperature $\left(\mathrm{T}_{\mathrm{e}}=45^{\circ} \mathrm{C}\right)$. The initial water content is around $w_{0}=0,2 \mathrm{Kg} / \mathrm{Kg}$ d.b.

Figures 4 and 5 show the temporal evolutions of the average temperature and average moisture content within the different earth bricks walls for 12 hours.

We observed that these curves have a same shape and that the average temperature increase and the moisture content decrease as time progresses. This due to the temperature 
gradient between wall and the surrounding medium. The heat supplied at the surfaces is used in the change of phase of the moisture from the liquid to the vapor at the surface. The moisture migrates toward the exchange surfaces by means of capillary, under the influence of a moisture content gradient [18].

Figures $4 \mathrm{a}$ and $5 \mathrm{a}$ show that, at the same conditions, the average temperature of the CEB wall is lower than the average temperature of the others walls. This is explained by the fact that the CEB thermal conductivity is small compared to that of SEB [6].In fact, experimental results show that the addition of cement or lime increase the thermal conductivity of the studied materials (figure 2). The thermal conductivity of stabilized soil lies in range of $0.8014-1.1 \mathrm{~W} /(\mathrm{mK})$ and $0.7902-0.9785 \mathrm{~W} /(\mathrm{mK})$ for respectively the cement content and the lime content. The increase of chemical stabilizer in earth bricks makes it less thermally insulated. Also, it can be seen from figures $4 \mathrm{~b}$ and $5 \mathrm{~b}$ that the rate of initial moisture loss decreases with an increase in chemical stabilizer content. These results indicate that moisture transfer in earth brick wall depend on the nature and dosage of the used chemical stabilizer.

This can be explained by the fact that the incorporation of the cement or the lime in the compressed earth bricks decreases its hygroscopicity and thus decreases the wall moisture diffusion toward the exchange surfaces. This result is in agreement with the experimental results (figures $3 a$ and $3 b$ ).

The superposition of sorption curves of CEB and SEB with different content of stabilizers (figure 3) indicates that stabilization considerably reduced the moisture sorption capacity of compressed earth brick. At high relative humidity $(97 \%)$ the maximum moisture content of cementearth brick are about 5.69 and $3.7 \%$ for cement content of $0 \%$ and $12 \%$ respectively. Lime stabilization reduced the maximum moisture content from $5.69 \%$ for $0 \%$ lime content to $3.76 \%$ when lime contents was $12 \%$ (figure 3 ).

This is explained by the fact that the chemical stabilization influences the pores size of soil-brick. Increasing stabilizer content increases the hydration products filling the spaces between soil particles and reducing the paths for water ingression. Therefore, the addition of chemical stabilizers enhances the heat transfer through the earthen materials and reduces their sorption capacity.

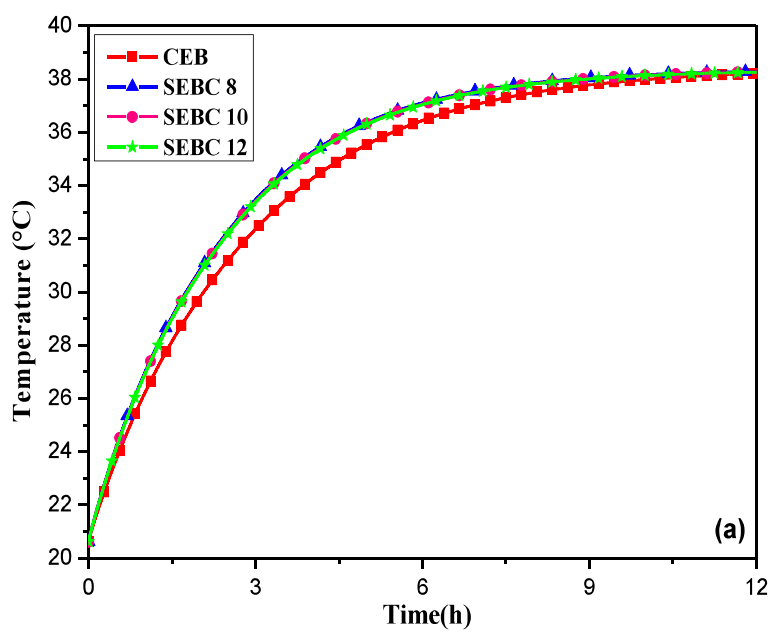

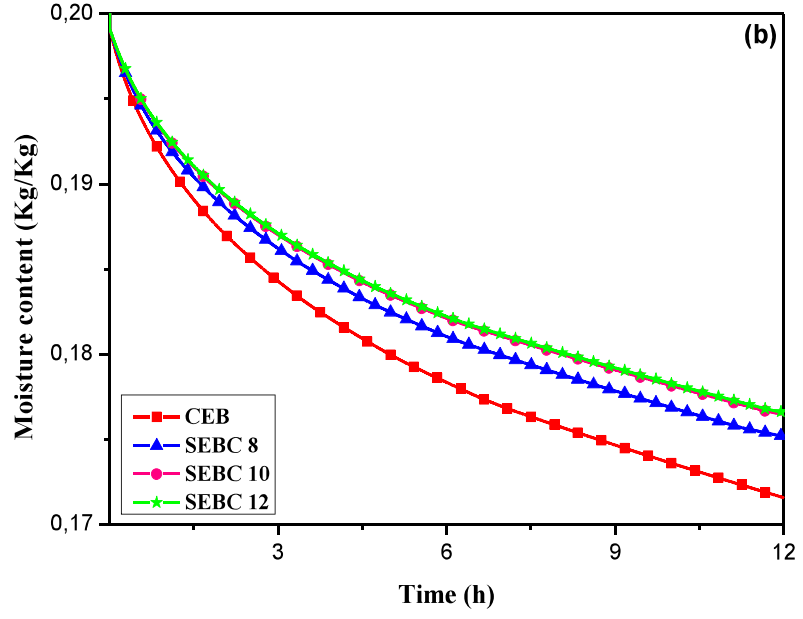

Figure 4

Average temperature (a) and average moisture content (b) of the SEBC walls

\section{Conclusions}

The objective of this paper was to investigate the behavior of building walls made with compressed earth brick and stabilized earth brick with incorporation of cement or lime. We have performed numerical simulation to study the hygrothermal behavior of walls subject to climatic conditions. Luikov's model is chosen for the formulation of the equations governing the heat and mass transfer phenomena. The problem was tackled by a numerical approach based on the implicit finite difference scheme. The obtained results illustrate the temporal evolutions of the temperature and the moisture content within the different walls for 12 hours.

We can conclude that the addition of chemical stabilizer (cement or lime) in earth bricks during its mixing makes it less hygroscopic and less thermally insulated.

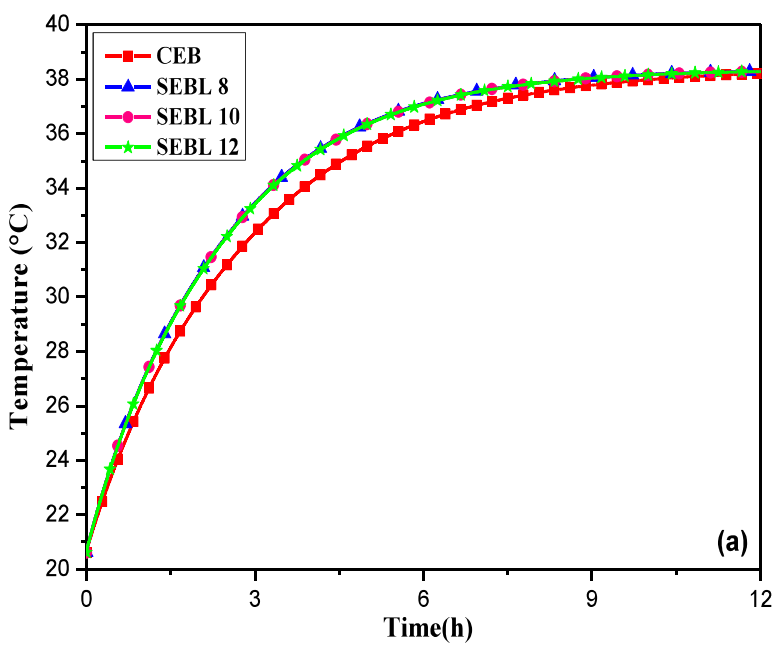




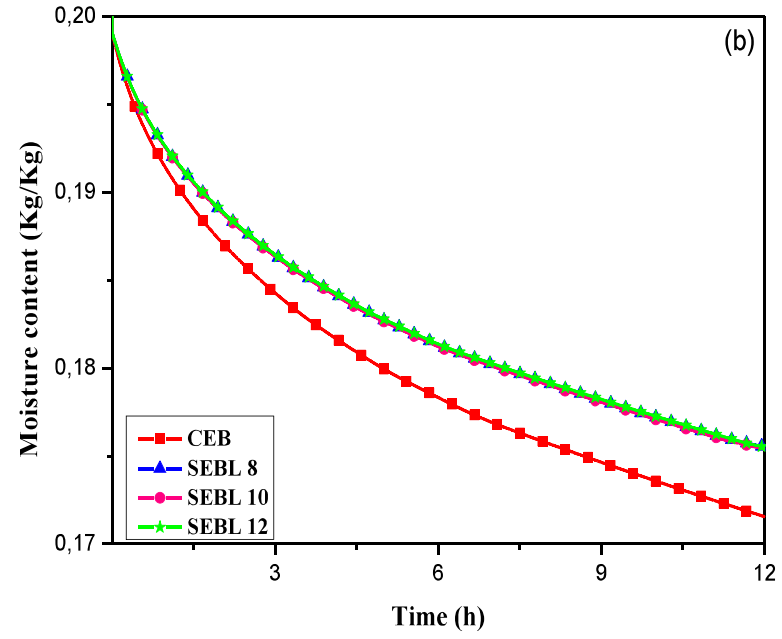

Figure 5

Average temperature (a) and average moisture content (b) of the SEBL walls

\section{References}

1. D. Pittet, K.S. Jagadish, T. Kotak, Environmental Impacts of Building Technologies: A Comparative Study in Kutch District,India, and Innovations for Development, Springer-Verlag France, pp. 113-128, 2012.

2. H. Cagnon, J.E. Aubert, M. Coutand, C. Magniont, Hygrothermal properties of earth bricks, Energy Build. 80, 208-217, 2014.

3. Q.B. Bui, J.C. Morel, B.V. Venkatarama Reddy, W. Ghayad, Durability of rammed earth walls exposed for 20 years to natural weathering, Build. Environ. 44, 912-919, 2009.

4. F.G. Bell, Engineering Treatment of Soils: Soil Stabilization, first Ed, E and FN Spon, UK, 1993.

5. B.N. Alfred, Improving the traditional earth construction: a case study of Botswana, Constr. Build. Mater. 11 (1997) 1-7.

6. M .Saidi, A.S. Cherif, B. Zeghmati, E. Sediki. Stabilization effects on the thermal conductivity and sorption behavior of earth bricks. Construction and Building Materials 167, 566-577,2018.

7. A. Arrigoni, A.C. Grillet, R. Pelosato, G. Dotelli, C.T.S. Beckett, M. Woloszyn, D. Ciancio, Reduction of rammed earth's hygroscopic performance under stabilisation: an experimental investigation, Build. Environ. 115, 358-367, 2017.

8. A.J. Fopossi, R.N. Mutuku, F. Ngapgue, Effects of stabilizers on water absorption of compressed earth blocks made from Mangu soil, Int. J. Eng. Sci. Emerg. Tech. (IJESET) 1, 490-495,2014.

9. N.C. Balaji, M.Mani, B.V.Reddy, Thermal conductivity studies on Cement stabilised soil blocks, Proc. Inst. Civil Eng. Constr. Mater. 170 (1), 40-54, 2017.
10. J.R.Philip, D.A.De Vries. Moisture movement in porous materials under temperature gradients. Transaction, American Geophysical Union,38(2) ,1957.

11. A.V.Luikov, Application of methods of thermodynamics of irreversible processes to investigation of heat and mass transfer in boundary layer, International journal of heat and mass transfer, 3,167-174,1961.

12. S.Whitaker Simultaneous Heat, mass, and Momentum transfer in Porous Media: A theory of drying, Advances in heat transfer, v.13,119-203,1977

13. E.F. Nogotov, Applications of numerical heat transfer. Hemisphere, Washington. 1978.

14. J.Y. Liu, S. Cheng, Solution of Luikov equations of heat and mass transfer in capillary porous bodies, International Journal of Heat and Mass Transfer 34,17471754,1991 .

15. M.Saidi. Study of hygrothermal transfer in an ecological material.Phd Thesis, University of Tunis El Manar, Tunisia,2018.

16. S.M. Henderson, A basic concept of equilibrium moisture, Agri. Eng. 33, 29-32,1952.

17. F. McGregor, A. Heath, A. Shea, M. Lawrence, The moisture buffering capacity of unfired clay masonry, Building and Environment 82, 599-607, 2014.

18. R.Younsi, D.Kocaefe, Y.Kocaefe. Three dimensional simulation of heat and moisture transfer in wood. Applied Thermal Engineering 26, 1274-1285,2006. 